\title{
CZU:633.854.78:631.52 https://doi.org/10.53040/gppb7.2021.52 \\ STUDIUL UNOR TRĂSĂTURI ASOCIATE CU PRODUCTIVITATEA LA HIBRIZI EXPERIMENTALI DE FLOAREA-SOARELUI
}

\author{
Clapco Steliana $^{1}$, Cucereavîi Aliona ${ }^{1,2}$, Gîscă I. $^{1,2}$, Duca Maria $^{1}$ \\ ${ }^{1}$ Centrul de Genetică Funcţională, Universitatea de Stat din Moldova, Chişinău, Republica Moldova, \\ ${ }^{2}$ AMG -Agroselect Comerţ, Soroca, Republica Moldova \\ e-mail: clapcostela@gmail.com
}

\begin{abstract}
The relationships between seed yield and some morpho-physiological parameters, such as plant height, head diameter, leaf number, number and weight of total and full seeds per head and 1000 seeds in 32 local hybrids has been studied. The analyses of Pearson correlation coefficients showed significant, but low, positive correlations between yield and number of full seeds per calatidium, weight of total seeds per calatidium, weight of 1000 seeds and hectolitre weight. There were also observed positive correlations between plant height and number of leaves.
\end{abstract}

Key words: sunflower, hybrids, productivity indices, Pearson correlation coefficients, significant correlations

\section{Introducere}

Floarea-soarelui (Helianthus annuus L.) este una dintre cele mai importante culturi oleaginoase din lume, seminţele acesteia fiind bogate în ulei (35-50\%) cu un conţinut ridicat de acizi graşi nesaturaţi şi vitamine, precum şi proteine (35\%), carbohidraţi (18-20\%) [13]. Cultivată pe aproximativ 25 de milioane de hectare, cu o producţie anuală de 40 de milioane de tone, cultura ocupă locul cinci printre plantele oleaginoase. Majoritatea $(85 \%)$ din seminţele de floarea-soarelui importate în Europa provin din comerţul intra-european, Republica Moldova fiind unul dintre furnizorii importanţi. Astfel, în 2017, Moldova a fost cel mai mare exportator de seminţe de floarea-soarelui printre ţările europene în curs de dezvoltare, contribuind cu 330 de mii de tone, ceea ce constituie 10\% din totalul livrărilor [1].

Ţinând cont de importanţa economică şi rolul deosebit al culturii de floarea-soarelui în nutriţia umană, creşterea producţiei mondiale a acesteia este una dintre priorităţile actuale. Dezvoltarea hibrizilor cu productivitate ridicată, îmbinată cu utilizarea unor practici agronomice adecvate reduce impactul factorilor limitativi şi contribuie la creşterea randamentului de floarea-soarelui [11]. Pe de altă parte, se cunoaşte că genotipurile locale sunt mai bine adaptate la condiţiile agroecologice specifice şi ar putea oferi o productivitate mai stabilă, comparativ cu formele străine.

Producţia de seminţe este o trăsătură complexă, dependentă de un şir de elemente constitutive ce relaţionează între ele, corelând negativ sau pozitiv cu productivitatea. Cunoaşterea trăsăturilor asociate cu productivitatea şi a interacţiunii dintre acestea este deosebit de importantă pentru relevarea componentelor cu influenţă substanţială asupra productivităţii, selecţia formelor cu caracteristici dezirabile şi, respectiv, eficientizarea programelor de ameliorare [5]. În cazul florii-soarelui elementele de productivitate sunt reprezentate de diametrul calatidiului, numărul de seminţe pline per calatidiu şi greutatea acestora, masa a 1000 boabe. Au fost raportate diferite corelaţii dintre numărul de frunze per plantă, durata fazelor de dezvoltare fenologică, randamentul de seminţe, ulei, proteine, masa a 1000 de seminţe şi alte caractere în diferite linii de floarea soarelui şi combinaţiile lor hibride $[3,5,6,8,11,12]$.

În contextul celor expuse, studiile prezentate în lucrarea dată au fost focusate asupra analizei caracteristicilor morfologice şi de producţie la un şir de hibrizi experimentali autohtoni.

\section{Materiale şi metode}

În studiu a fost inclus un set de 32 combinaţii hibride obţinute în cadrul companiei AMG-Agroselect Comerţ în baza unor forme parentale de origine diferită (resurse genetice locale, europene şi cele provenite din colecţiile VNIIMK şi VIR). Cercetările au fost realizate pe câmpurile experimentale ale companiei amplasate în raionul Soroca. Testarea indicilor morfologici şi de producţie ai hibrizilor s-a efectuat în cultura comparativă de concurs (CCC) pe parcele de câte 6 rânduri cu suprafaţa de $33,6 \mathrm{~m}^{2}$ în trei repetiţii. 
La înflorire şi recoltare au fost determinate diferite trăsături morfologice şi agronomice, precum: înălţimea plantelor $(\mathrm{cm})$, numărul de frunze pe o plantă, diametrul calatidiului $(\mathrm{cm})$, numărul de seminţe pline per calatidiu, masa seminţelor de pe un calatidiu (g), masa a 1000 boabe (g), masa hectolitrică $(\mathrm{kg} / \mathrm{hl})$, recolta medie (t/ha). Valoarea medie a înălţimii plantelor şi a diametrului calatidiului s-a determinat în câmp, prin măsurări realizate la 10 plante din fiecare repetiţie. Numărul mediu de seminţe per calatidiu s-a apreciat prin numărarea tuturor seminţelor pline din calatidiile a 10 plante, pentru fiecare bloc luat în studiu şi fiecare repetiţie. Masa a 1000 de boabe (MMB) s-a determinat în laborator, prin numărarea a două probe a câte 500 seminţe, cântărirea acestora, calculul mediei între probe şi înmulţirea la doi, pentru fiecare genotip şi repetiţie. Masa hectolitrică s-a determinat prin cântărirea a 2 probe a unui volum de un litru de seminţe cu ajutorul balanţei, calculul mediei probelor pentru 10 plante din fiecare număr luat în studiu şi fiecare repetiţie. Analizele au fost efectuate pe parcursul a doi ani, datele reflectate în lucrare reprezentând valorile medii ale parametrilor.

\section{Rezultate şi discuţii}

Analizând un şir de însuşiri asociate cu productivitatea la hibrizii creaţi prin încrucişarea liniilor de floarea-soarelui obţinute din diferite surse genetice, constatăm că acestea variază în limitele de: înălţimea medie a plantei - 1,25 şi 1,74 m; numărul de frunze per tulpină - 28,0 şi 36,0 bucăţi; diametrul calatidiului - 17,0 şi 20,0 cm; numărul de seminţe pline per calatidiu - 971 şi 1469; masa seminţelor pline per calatidiu - 49,2 şi 84,5 g; masa hectolitrică - 34,2 şi 43,1 kg/hl; masa a 1000 de seminţe - 49,1 şi 71,2 g, recolta este cuprinsă între 2,15 şi 3,27 t/ha (Tabelul 1). Hibrizii testaţi prezintă o variabilitate mai mare, în special, după caracterul numărul de seminţe pline per calatidiu şi masa a 1000 de seminţe, coeficientul de variaţie constituind cca $11 \%$, iar cel mai puţin variabil a fost diametrul calatidiului $(\mathrm{CV}=4,5 \%)$.

Una dintre trăsăturile morfologice ale culturii de floarea-soarelui deosebit de importantă în procesul de ameliorare este înălţimea plantelor, formele cu talie mai joasă fiind mai bine adaptate la recoltarea mecanizată. Astfel, pentru obţinerea recoltei înalte şi sporirea rezistenţei la cădere este necesar de a crea hibrizi cu înălţimea de 120-150 cm [2]. Dintre genotipurile evaluate, în limitele menţionate se înscriu preponderent combinaţiile ce includ în calitate de linie paternă forma $R f-5$ şi $R f-10$.

Conform datelor obţinute de Marinkovic [10], înălţimea plantelor exercită un efect pozitiv asupra randamentului seminţelor. În studiile prezente, nu au fost stabilite corelaţii semnificative ( $p<0,01$ sau 0,05) între înălţimea plantelor şi randamentul seminţelor (Tabelul 2), datele fiind în concordanţă cu cele obţinute de Papatheohari şi colab. [12]. S-a constatat că talia plantelor corelează semnificativ (nivelul de semnificaţie $\mathrm{p}<0,01)$ cu numărul de frunze per plantă, coeficientul de corelaţie Pearson constituind $r=0,4232$ (Tabelul 2). Similar rezultatelor raportate de Hladni şi colab. [6] şi Khan şi colab. [9], care au stabilit o puternică corelaţie pozitivă a numărului total de frunze per plantă cu randamentul de floareasoarelui şi conţinutul de ulei în seminţe, în studiul prezent, au fost observate corelaţii semnificative (nivelul de semnificaţie $\mathrm{p}<0,05)$ între numărul de frunze şi masa a 1000 de seminţe $(r=0,3605)$.

O altă însuşire importantă în structura randamentului seminţelor de floarea-soarelui este diametrul calatidiului, care influenţează numărul de flori şi seminţe per plantă şi, respectiv, productivitatea culturii. În cazul hibrizilor studiaţi, valorile acestui parametru sunt similare celor stabilite de alţi autori [7, 9].

Datele prezentate în tabelul 2 evidenţiază corelaţii semnificative $(\mathrm{p}<0,05)$ medii între diametrul calatidiului şi masa seminţelor per calatidiu $(r=0,3332)$, precum şi masa hectolitrică $(r=0,3913)$. Corelaţii pozitive între indicatorii menţionaţi au fost raportate inclusiv de Hladni şi colab. [6], Kaya şi colab. [8], Khan şi colab. [9]. Coeficienţii de corelaţie determinaţi sunt însă mai mici comparativ cu cei relevaţi întrun studiu similar [3]. Cea mai înaltă valoare a coeficientului de corelaţie $(r=0,4701$, nivelul de semnificaţie $p<0,01) \mathrm{s}-\mathrm{a}$ constatat între numărul şi masa seminţelor per calatidiu.

În conformitate cu datele obţinute principalii parametri asociaţi cu randamentul seminţelor de floarea-soarelui (recolta, t/ha) sunt numărul de seminţe pline per calatidiu $(r=0,3404)$, masa seminţelor per calatidiu $(r=0,3796)$ şi cea a 1000 de seminţe $(r=0,3451)$, cât şi masa hectolitrică $(r=0,3505)$. Corelaţii pozitive între trăsăturile menţionate şi productivitate au fost raportate de Hladni şi colab. [6], Goksoy şi Turan [4]. 
Tabelul 1. Principalele caracteristici morfologice ale combinaţilor hibride noi de floarea-soarelui AMG-Agroselect Comerţ SRL

\begin{tabular}{|c|c|c|c|c|c|c|c|c|}
\hline $\begin{array}{c}\text { Combinaţia } \\
\text { hibridă }\end{array}$ & $\begin{array}{c}\text { Înălţimea } \\
\text { plantei, } \\
\text { m }\end{array}$ & $\begin{array}{c}\text { Numărul de } \\
\text { frunze }\end{array}$ & \begin{tabular}{|c|}
$\begin{array}{c}\text { Diametrul } \\
\text { calatidiului, } \\
\mathrm{cm}\end{array}$ \\
\end{tabular} & $\begin{array}{l}\text { Numărul de } \\
\text { seminţe pline } \\
\text { per calatidiu }\end{array}$ & $\begin{array}{l}\text { Masa semi- } \\
\text { nţelor per } \\
\text { calatidiu, g }\end{array}$ & \begin{tabular}{|c|} 
Masa \\
hectolitrică, \\
kg/hl \\
\end{tabular} & MMB, g & $\begin{array}{c}\text { Recolta } \\
\text { medie, } \\
\text { t/ha }\end{array}$ \\
\hline MS-1 × $R f-1$ & 1,67 & 31 & \begin{tabular}{|l|}
19 \\
\end{tabular} & 1103 & 73,3 & 38,3 & 71,2 & 2,97 \\
\hline MS-2 × $R f-1$ & 1,59 & 29 & 19 & 1180 & 75,4 & 42,1 & 64,9 & 2,93 \\
\hline MS-3 × $R f-1$ & 1,69 & 29 & 17 & 1041 & 76,1 & 37,6 & 70,4 & 2,90 \\
\hline MS-4 × $R f-1$ & 1,47 & 29 & 18 & 1084 & 71,5 & 37,3 & 69,0 & 2,72 \\
\hline MS-5 × $R f-1$ & 1,70 & 32 & 19 & 997 & 72,9 & 39,7 & 70,1 & 2,71 \\
\hline MS-6 × $R f-1$ & 1,74 & 36 & 17 & 1031 & 65,5 & 38,2 & 66,5 & 2,93 \\
\hline MS-7 × $R f-1$ & 1,63 & 32 & 18 & 1236 & 80,5 & 40,8 & 70,7 & 2,75 \\
\hline MS-1 × $R f-4$ & 1,65 & 33 & 19 & 998 & 72,1 & 40,9 & 53,8 & 2,72 \\
\hline MS-2 × $R f-4$ & 1,52 & 32 & 18 & 1317 & 73,7 & 41,2 & 50,4 & 2,94 \\
\hline MS-3 × $R f-4$ & 1,57 & 34 & 19 & 1119 & 75,2 & 40,9 & 51,6 & 3,07 \\
\hline MS-4 x $R f-4$ & 1,66 & 32 & 17 & 1008 & 70,1 & 40,9 & 51,8 & 2,69 \\
\hline MS-5 × $R f-4$ & 1,69 & 33 & 20 & 1012 & 80,4 & 40,9 & 51,9 & 2,91 \\
\hline MS-6 × $R f-4$ & 1,70 & 34 & 18 & 1297 & 77,9 & 39,7 & 51,6 & 2,52 \\
\hline MS-7 × $R f-4$ & 1,72 & 34 & 19 & 1050 & 69,8 & 42,8 & 49,1 & 2,64 \\
\hline MS-1 x $R f-5$ & 1,55 & 30 & 19 & 1469 & 84,5 & 41,5 & 61,3 & 3,23 \\
\hline MS-2 × $R f-5$ & 1,48 & 28 & 19 & 1218 & 72,8 & 43,1 & 63,2 & 3,27 \\
\hline MS-3 x $R f-5$ & 1,55 & 29 & 18 & 1229 & 83,5 & 34,2 & 67,4 & 3,13 \\
\hline MS-4 × $R f-5$ & 1,31 & 30 & 19 & 1097 & 78,1 & 41,5 & 68,7 & 3,19 \\
\hline$M S-5 \times R f-5$ & 1,42 & 30 & 18 & 1182 & 69,3 & 42,5 & 64,3 & 3,17 \\
\hline MS-6 × $R f-5$ & 1,48 & 33 & 20 & 1182 & 83,2 & 40,4 & 61,8 & 2,87 \\
\hline MS-7 x $R f-5$ & 1,42 & 29 & 18 & 1370 & 74,7 & 40,3 & 58,3 & 2,84 \\
\hline MS-1 × $R f-6$ & 1,63 & 32 & 19 & 1039 & 73,2 & 38,5 & 55,2 & 2,24 \\
\hline MS-2 × $R f-6$ & 1,49 & 29 & 18 & 1115 & 66,5 & 39,2 & 57,1 & 2,34 \\
\hline MS-3 x $R f-6$ & 1,59 & 30 & 18 & 1093 & 74,3 & 37,9 & 60,3 & 2,39 \\
\hline MS-4 × $R f-6$ & 1,25 & 29 & 19 & 1002 & 69,5 & 38,0 & 55,9 & 2,15 \\
\hline MS-1 x $R f-10$ & 1,56 & 35 & 17 & 1251 & 75,5 & 38,2 & 59,8 & 2,66 \\
\hline$M S-2 \times R f-10$ & 1,37 & 31 & 18 & 1334 & 74,3 & 40,1 & 59,8 & 2,64 \\
\hline MS-3 x $R f-10$ & 1,46 & 30 & 18 & 1196 & 67,4 & 39,6 & 59,6 & 2,72 \\
\hline MS-4 x $R f-10$ & 1,27 & 32 & 18 & 1220 & 78,1 & 39,2 & 67,1 & 2,78 \\
\hline$M S-5 \times R f-10$ & 1,42 & 31 & 17 & 1187 & 67,6 & 38,9 & 60,6 & 2,75 \\
\hline MS-6 × $R f-10$ & 1,45 & 34 & 18 & 1218 & 71,0 & 38,9 & 58,5 & 2,61 \\
\hline MS-7 x $R f-10$ & 1,45 & 32 & 18 & 971 & 49,2 & 38,4 & 58,2 & 2,55 \\
\hline V.max & 1,74 & 36 & 20 & 1469 & 84,5 & 43,1 & 71,2 & 3,27 \\
\hline V.min & 1,25 & 28 & 17 & 971 & 49,2 & 34,2 & 49,1 & 2,15 \\
\hline Media & 1,54 & 31,4 & 18,3 & 1151,4 & 73,4 & 39,7 & 60,6 & 2,8 \\
\hline DS & 0,13 & 2,08 & 0,82 & 124,5 & 6,6 & 1,9 & 6,7 & 0,3 \\
\hline $\mathrm{CV}(\%)$ & 8,7 & 6,6 & 4,5 & 10,8 & 8,9 & 4,7 & 11,0 & 9,9 \\
\hline
\end{tabular}

Tabelul 2. Coeficienţii Pearson de corelaţie dintre unele caractere morfo-fiziologice şi de productivitate la combinaţiile hibride de floarea-soarelui

\begin{tabular}{|c|c|c|c|c|c|c|c|}
\hline Trăsături & $\mathrm{X2}$ & $\mathbf{X 3}$ & $\mathrm{X} 4$ & X5 & X6 & $\mathrm{X} 7$ & X8 \\
\hline $\mathrm{X1}$ & $0,4232^{*}$ & $0,0090^{\mathrm{ns}}$ & $0,2799^{\text {ns }}$ & $0,1041^{\mathrm{ns}}$ & $0,1047^{\mathrm{ns}}$ & $0,2100^{\mathrm{ns}}$ & $0,0335^{\text {ns }}$ \\
\hline $\mathrm{X} 2$ & - & $0,0521^{\mathrm{ns}}$ & $0,1457^{\mathrm{ns}}$ & $0,0621^{\mathrm{ns}}$ & $0,3605^{* * *}$ & $0,0597^{\mathrm{ns}}$ & $-0,1351^{\mathrm{ns}}$ \\
\hline $\mathrm{X3}$ & - & - & $0,1176^{* * *}$ & $0,3332^{* *}$ & $0,1354^{\mathrm{ns}}$ & $0,3913^{* *}$ & $0,1361^{\mathrm{ns}}$ \\
\hline $\mathrm{X} 4$ & - & - & - & $0,4701^{*}$ & $0,0259^{\text {ns }}$ & $0,0707^{\mathrm{ns}}$ & $0,3404^{* *}$ \\
\hline $\mathrm{X} 5$ & - & - & - & - & $0,1795^{\mathrm{ns}}$ & $0,3026^{\mathrm{ns}}$ & $0,3796^{* *}$ \\
\hline $\mathrm{X6}$ & - & - & - & - & - & $0,3451^{* *}$ & $0,3451^{* *}$ \\
\hline $\mathrm{X} 7$ & - & - & - & - & - & - & $0,3505^{* *}$ \\
\hline \multicolumn{5}{|c|}{$\begin{array}{l}\text { X1 - Înălţimea plantelor (cm) } \\
\text { X2 - Numărul total de frunze per plantă } \\
\text { X3 - Diametrul calatidiului (cm) } \\
\text { X4 - Numărul de seminţe pline per calatidiu } \\
\text { X5 - Masa semințelor per calatidiu (g) }\end{array}$} & \multicolumn{3}{|c|}{$\begin{array}{l}\text { X6 - Masa a } 1000 \text { de seminte }(\mathrm{g}) \\
\text { X7 - Masa hectolitrică }(\mathrm{kg} / \mathrm{hl}) \\
\text { X8 - Recolta medie (t/ha) }\end{array}$} \\
\hline
\end{tabular}




\section{Concluzii}

Analiza coeficienţilor de corelaţie Pearson dintre parametrii morfologici şi de productivitate la 32 de hibrizi experimentali autohtoni au pus în evidenţă corelaţii pozitive semnificative, însă scăzute, dintre recoltă şi numărul de seminţe pline per calatidiu, masa seminţelor per calatidiu, masa a 1000 de seminţe şi masa hectolitrică. De asemenea, s-au relevat corelaţii pozitive dintre masa şi numărul seminţelor per calatidiu şi corelaţii între înălţimea plantei şi numărul de frunze.

Cercetările prezentate în lucrare au fost realizate în cadrul proiectului 20.80009.5107.01 "Studii geneticomoleculare şi biotehnologice ale florii-soarelui în contextul asigurării managementului durabil al ecosistemelor agricole”, finanțat de Agenția Națională pentru Cercetare și Dezvoltare.

\section{Bibliografie}

1. CBE - Centre for the Promotion of Imports, Ministry of Foreign Affairs of Netherlands. (2019). Exporting sunflower seeds to Europe, disponibil la www.cbi.eu (Accesat 27 martie 2021)

2. ĆIRIĆ, M., JOCIĆ, S., CVEJIĆ, S. et al. Combining abilities of new inbred lines of sunflower (Helianthus annuus L.). Genetika, 2013, 45(2):289-296.

3. CLAPCO, S., GISCA, I., CUCEREAVII, A., DUCA, M. Analysis of yield and yield related traits in some sunflower (H. annuиs) hybrids under conditions of the Republic of Moldova, Agro Life Scientific Journal, 2019, 8:2:248258.

4. GOKSOY, A.T., TURAN, Z. M. Correlations and path analysis of yield components in synthetic varieties of sunflower (Helianthus annuus L.), Acta Agronomica Hungarica, 2007, 55(3):339-345.

5. HASSAN, S.M.F., IQBAL, M.S., RABBANI, G. et al. Correlation and path analysis for yield and yield components in sunflower (Helianthus annus L.), African Journal of Biotechnology, 2013, 12(16):1968-1971.

6. HLADNI, N., JOCIĆ S., MIKLIČ, V. et al. Effect of morphological and physiological traits on seed yield and oil content in sunflower, Helia. 2010, 33(53):101-116.

7. IQRASAN, A., QAYYUM, S.U., KHAN, S.A. et al. Sunflower (H. annuиs) hybrids evaluation for oil quality and yield attributes under spring planting conditions of Haripur. Pakistan, Planta daninha, 2017, 35: e017161596.

8. KAYA, Y., EVCI, G., DURAK, S. et al. (). Yield components affecting seed yield and their relationships in sunflower (Helianthus annuus L.), Pakistan Journal of Botany, 2009, 41(5):2261-2269.

9. KHAN, H., SAFDA, A., IJA, A. et al. Agronomic and qualitative evaluation of different local sunflower hybrids, Pakistan Journal of Agricultural Research, 2018, (31)1:69-78.

10. MARINKOVIC, R. Path coefficient analysis of some yield components of sunflower (Helianthus annuus L.), Euphytica, 1992, 60:201-205.

11. MIKLIČ, V., BALALIĆ, I., JOCIĆ, S. et al. Stability estimation for seed and oil yield of NS sunflower hybrids in small-plot trials and recommendation for 2010 sowing season, Field Veg. Crop. Res., 2010, 47(1):131-146.

12. PAPATHEOHARI, Y., TRAVLO, I. S., PAPASTYLIANO, P. et al. Growth and yield of three sunflower hybrids cultivated for two years under Mediterranean conditions, Emirates Journal of Food and Agriculture, 2016, 28(2):136-142.

13. SKORIC, D., MARINKOVIC, R. Most recent results in sunflower breeding. Int. Symposium on sunflower, Budapest, Hungary, 1986, p. 118-127. 